\title{
Behaviour of S 355JO steel subjected to uniaxial stress at lowered and elevated temperatures and creep
}

\author{
JOSIP BRNIC*, MARKO CANADIJA, GORAN TURKALJ and DOMAGOJ LANC \\ Faculty of Engineering, University of Rijeka, Vukovarska 58, 51000 Rijeka, Croatia
}

MS received 17 March 2009; revised 16 April 2009

\begin{abstract}
This paper considers main mechanical properties of structural-high strength low alloy (HSLA) S 355JO (ASTM A709 Gr50) steel subjected to uniaxial tensile tests at lowered and elevated temperatures. The engineering stress vs strain diagrams as well as curve's dependence of ultimate and yield strengths vs both lowered and elevated temperatures are presented. The focus is also on specimen elongations vs temperature at elevated temperatures. Short-time creep tests for selected constant stresses at selected temperatures were curried out. Uniaxial creep behaviour for selected creep test was modeled by the rheological model. The creep curve determined by modeling procedure was compared with experimentally obtained one. Also, notch impact energy test, using Charpy pendulum impact machine was performed and according to the proposed formula, fracture toughness is calculated. All of experimental tests were performed using modern computer directed experimental systems.
\end{abstract}

Keywords. S 355JO steel; material mechanical properties; lowered temperature; elevated temperature; creep tests.

\section{Introduction}

Knowledge of material properties at lowered and elevated temperatures is of importance in structure design and its manufacturing. Namely, structure has to be designed according to its expected response at given environmental conditions. Structure lifetime prediction is closely linked with the possible mechanical failures caused by loads at mentioned environmental conditions. These failures may be defined as any change in the size, shape or material properties of a structure or its part that renders it incapable of satisfactorily performing its intended function, (Collins 1993). Manifestation of failure may be referred to as an elastic or plastic deformation, rupture or fracture and material change. In present time, structure design is based on high computer capacity supported by finite element analysis. Mechanical failures involve an extremely complex interaction of load, time and environment. Mechanical failure modes most commonly observed in engineering practice are usually listed as: force induced elastic deformation, yielding, fatigue, rupture, corrosion, wear, impact, creep, etc (Stephens et al 2001). Creep failure results in plastic deformation in structure member which accrues over a period of time under the influence of stress and temperature till the accumulated strains interfere with the ability of structure intended function. Creep is one of the most important and well recognized

\footnotetext{
*Author for correspondence (brnic@riteh.hr)
}

possible failure modes. In its simplest form creep may be defined as the progressive accumulation of plastic strain in a specimen or machine part under stress, at elevated temperature over a period of time. Sometimes, it can be easy to quantify damage in laboratory creep procedure conducted at constant stress (load) and temperature, but components of machines in service hardly ever operate under constant conditions (Timmins 1997). Creep may occur over a wide range of temperature, stress and time combination $(t, T, \sigma)$, and depends on the material and the environment. Creep is a thermally activated process and structural components should not be deformed by creep during service (Raghavan 2004). The classical representation of metal creep curve (figure 1), can be found in literature dealing with mechanical design and failure of materials.

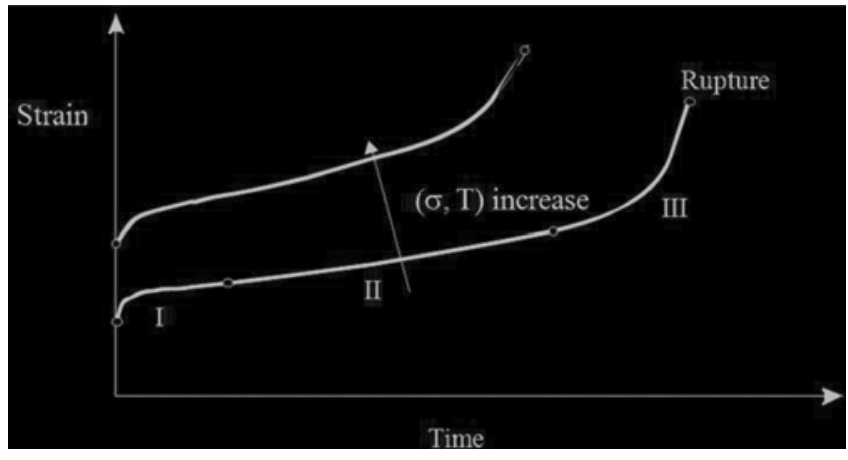

Figure 1. Classical representation of metal creep stages (I. primary, II. secondary, III. tertiary). 
Comparing the metal materials behaviour at elevated and lowered temperatures, someone can note that, in general, both ultimate and yield strengths decrease with increasing temperature while at decreasing temperature both of the mentioned strengths are growing. Ultimate and yield strengths, as well as material elongation, are of big importance in design of structure intended to be used at elevated temperatures, e.g. turbine rotors, pressure vessels, etc or at lowered temperatures, e.g. icebreaker or similar structure. Some of the published papers dealing with the general problems of the material under consideration can be found, but more data about mechanical properties at elevated and lowered temperatures as well as creep behaviour of this steel are not readily available. That is the reason for experimental investigations undertaken with the purpose to use obtained data in structure design procedure. If an overview of available data dealing with considered issues are done, then it can be specified as follows. An analysis of the behaviour of mechanical properties of different steels at elevated temperatures, including carbon steel S 355 , is presented by Outinen and Makelainen (2006). Furthermore, a fire model for structural steel S 355 is given by Outinen et al (1997). The problem of a hybrid steel girder is considered by Veljkovic and Johansson (2004). Usually, the flanges of girders are made of high strength steel and the web of a lower grade, say S355 steel. Such girders are more economical than homogenous ones. Some information of producing and application of steels, including similar steel considered in this paper, can be found. So, some companies, like Dillinger Hütte GTS, have been specialized in the production and supply of steel heavy plate for numerous applications within the offshore oil and gas industry including offshore structures, steel construction and shipbuilding, etc. Steel heavy plate produced according to specifications is manufactured further into offshore platforms, bridge girders, ships, skyscrapers, etc. Low temperature service conditions, like arctic application, represent an important challenge for today's structural steel plates. Low design temperatures require steels which exhibit good fracture toughness behaviour combined with high strength. In order to meet this new set of steel properties, an artic steel was developed, and a variant S 355 steel is one of them. In Hayward et al (2002), within the chapter titled 'Steel qualities/materials selection', it can be seen that S355 steel is more economically attractive than S 275 steel and so its use by designers and its availability have greatly increased. Thus, the advantageous properties of strength/mass steel S 355 also offer savings for transportation and assemblage. Current design codes for fire resistance of structure are based on isolated member tests subjected to standard fire conditions. The performance of the real structure subjected to real fires often surpasses the one predicted from tests due to structural continuity. Such analysis is done by Wald et al (2006), where some data related to S 355 steel are pre- sented. The behaviour of one type of high strength low alloy steel at elevated temperature is considered by Brnic et al (2009).

\section{Mechanical material properties}

\subsection{Material general data}

Structural steel S $355 \mathrm{JO}$ Gr50 with the following composition, wt (\%): C $(0.212)$, Si $(0.337)$, Mn $(1.31)$, P $(0 \cdot 0179), \mathrm{S}(0 \cdot 0104)$, Fe plus rest $(98 \cdot 11)$ has been examined. This kind of steel is the high strength low alloy steel (HSLA), which is usually used in high loaded structures like bridges, cranes as well as in general mechanical engineering because of its superior toughness, strength and weldability. When the steel is to be welded, it is presupposed that a welding procedure suitable for the grade of steel and intended use or service will be utilized. For structural products to be used as tension components required notch toughness testing and hence standardized requirements are provided.

\subsection{Testing systems}

The deployment of testing system depends on the level of temperature involved. Testing system for experimental investigations at lowered temperatures among the testing machine Zwick Roell Z400E consists also of Zwick Roell temperature chamber, BW91250 and macro extensometer, while system for experimental investigations at elevated temperatures covers apart from testing machine and high temperature furnace, $900^{\circ} \mathrm{C}$ and high temperature extensometer (figure 2). Charpy pendulum impact machine used in notch impact energy determination is shown in figure 3 .

\subsection{Testing procedures}

In these experimental investigations, according to the level of the required temperature, two kinds of testing procedures may be distinguished. The one is related to the uniaxial tensile tests at lowered temperatures and the other one is related to the uniaxial tensile tests at elevated temperatures. Mechanical properties at ambient temperature were determined according to the EN 10002-1 (ASTM E8) standard, at lowered temperatures according to ISO $15579: 2000$ (E) standard, while mechanical properties at elevated temperatures were determined according to EN 10002-5 (ASTM E21) standard. Testing procedures for obtaining material creep behaviour according to ASTM E139 standard were carried out. To determine notch impact energy, the test was carried out according to ASTM E23-05 standard (2005). All of experimental tests were performed at the Laboratory of the Department of Engineering Mechanics, Faculty of Engineering, Rijeka. 


\subsection{Specimens}

The test specimens were taken from structural HSLA S $355 \mathrm{JO}$ steel rods. They were prepared according to ISO $15579: 2000$ (E) standard or ASTM E8M-04 standard (EN 10002-1:2001) or ASTM E 23-05 standard, depending on required temperature of experimental procedure. One specimen used in experimental procedure is presented in figure 4 .

\subsection{Engineering stress-strain diagrams}

2.5a Lowered temperatures: According to the engineering stress-strain diagrams (figure 5), appropriate numerical data are presented in table 1.

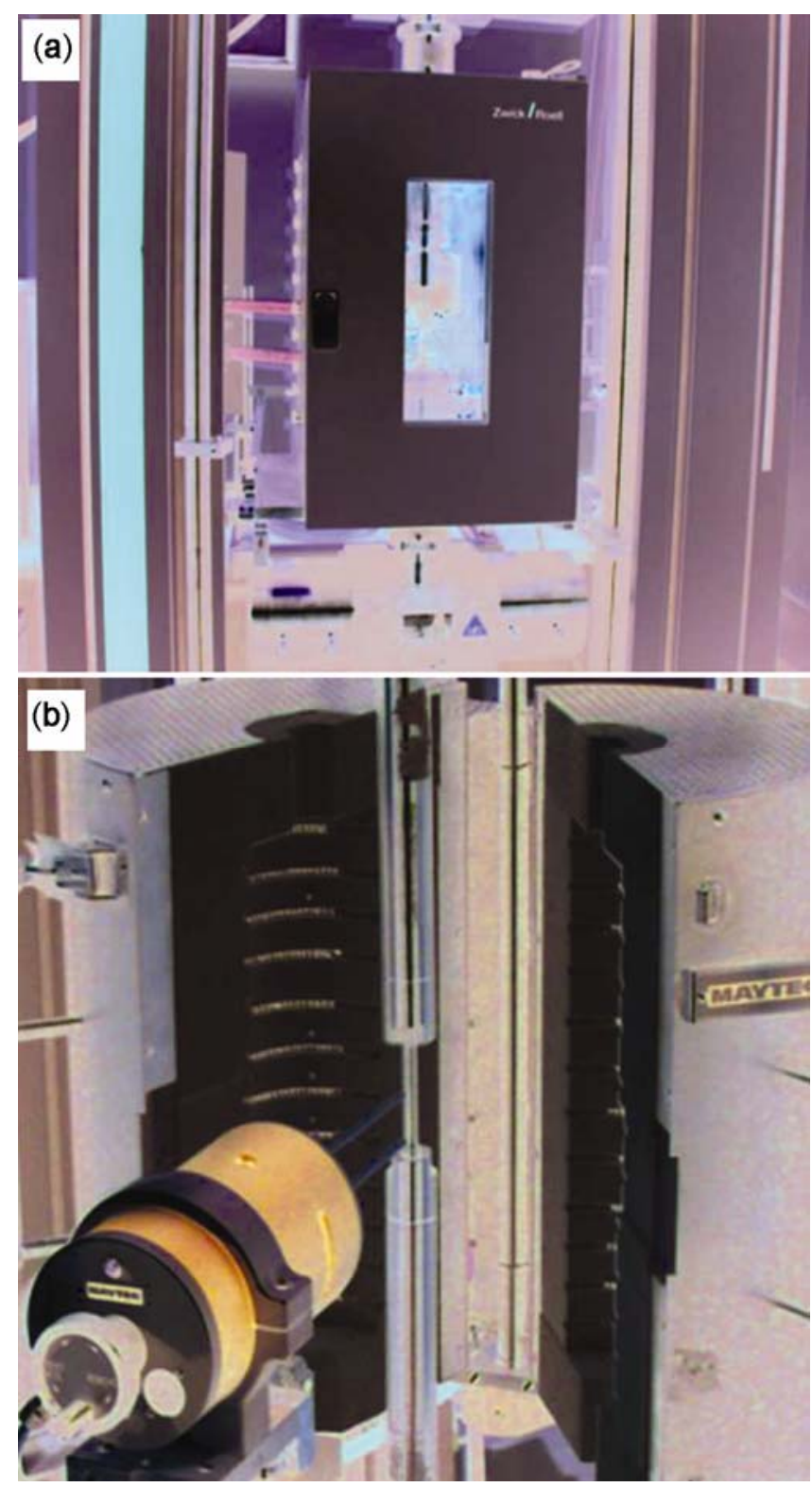

Figure 2. Testing systems: (a) lowered temperatures and (b) elevated temperatures
The curves representing ultimate tensile strength and $0 \cdot 2$ offset yield strength of S $355 \mathrm{JO}$ steel at lowered temperatures are presented in figure 6 .

From the results presented relating to lowered temperatures, it is visible that ultimate tensile strength increases on decreasing temperature, except at the temperature of

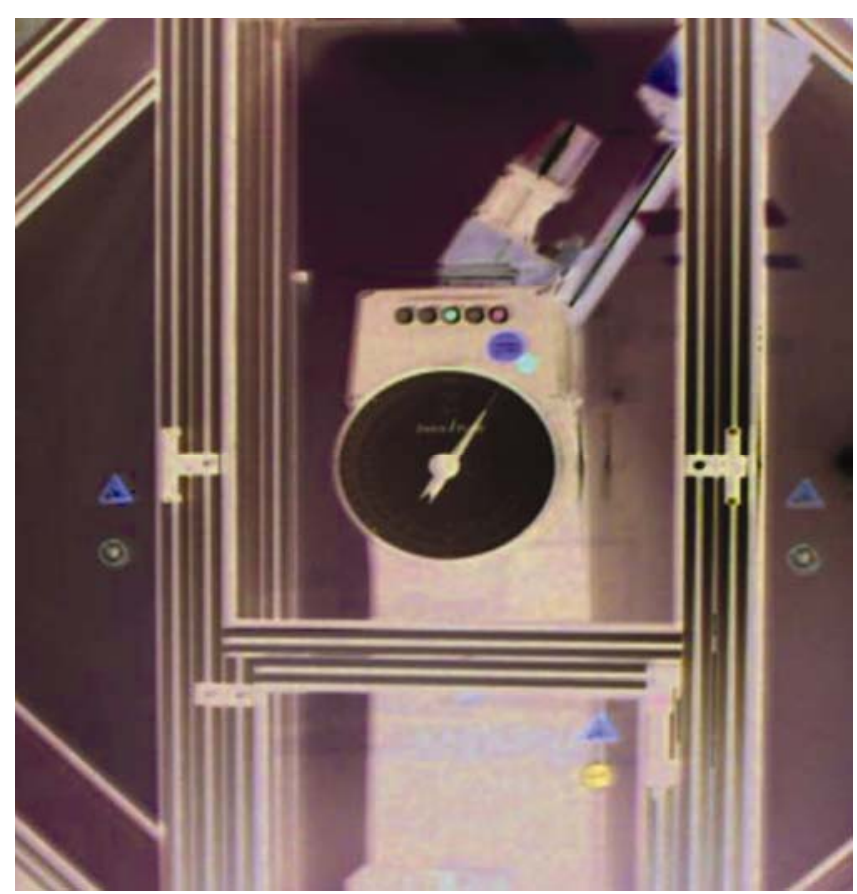

Figure 3. Charpy pendulum impact machine.

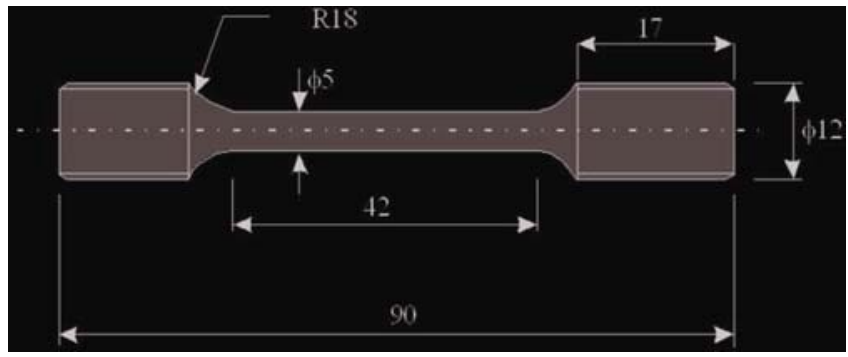

Figure 4. Geometry of specimen

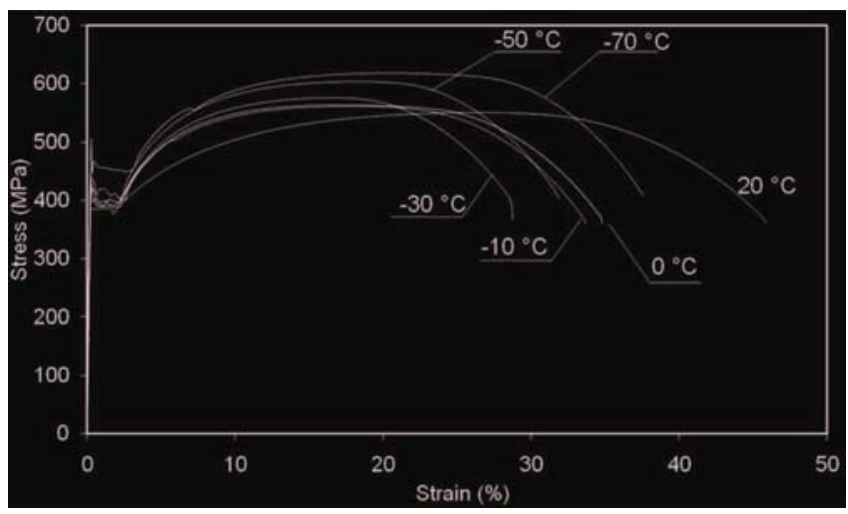

Figure 5. Stress-strain behaviour of S 355JO steel at lowered temperatures. 
$\left(-10^{\circ} \mathrm{C}\right)$ where it decreases slightly. Similar growth exhibits 0.2 offset yield strength but at temperatures of $\left(-30^{\circ} \mathrm{C}\right)$ and $\left(-50^{\circ} \mathrm{C}\right)$ it decreases slightly.

2.5b Elevated temperatures: Stress-strain diagrams of $\mathrm{S} 355 \mathrm{JO}$ at elevated temperatures are presented in figure 7. Numerical data of ultimate tensile strength and 0.2 offset yield strength of S $355 \mathrm{JO}$ steel at elevated temperatures are given in table 2 .

Effect of elevated temperatures on mechanical and other properties of $\mathrm{S} 355 \mathrm{JO}$ steel are presented in figure 8 .
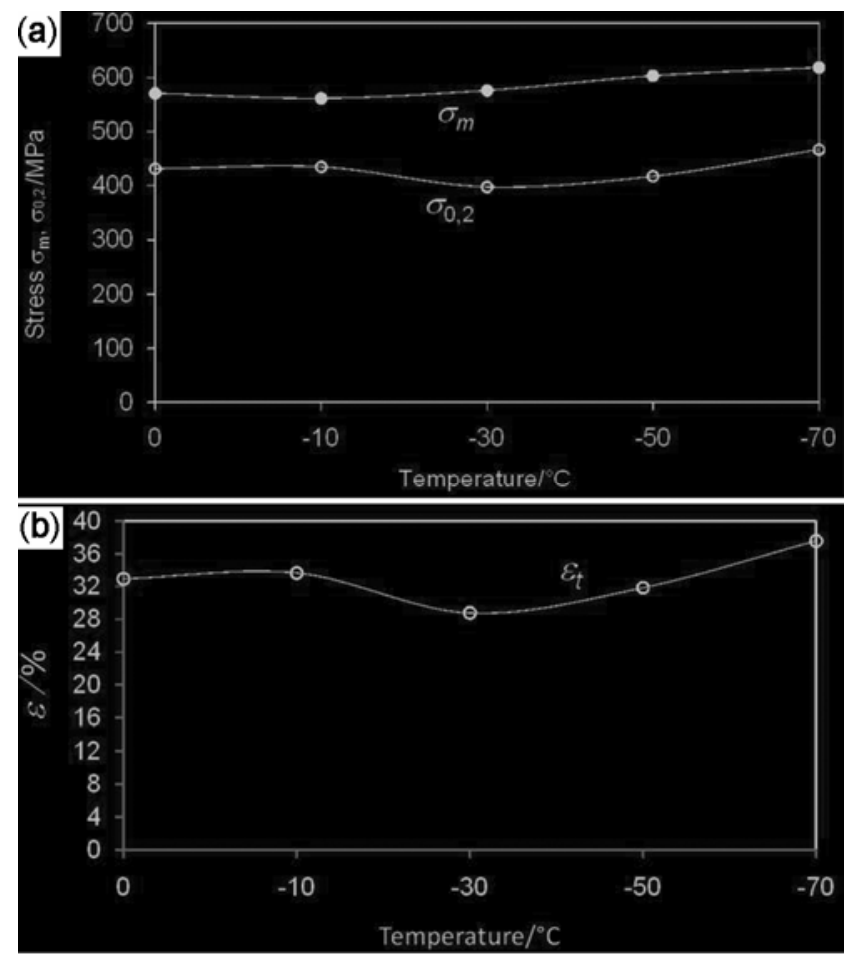

Figure 6. Effect of lowered temperature on both mechanical properties and elongation of S 355JO steel; (a) mechanical properties $\sigma_{\mathrm{m}}$ and $\sigma_{0.2}$ vs temperature ( $\sigma_{\mathrm{m}}$, ultimate tensile strength, $\sigma_{0.2}, 0.2$ offset yield strength) and (b) specimen's elongation vs temperature ( $\varepsilon_{\mathrm{t}}$, strain at break).

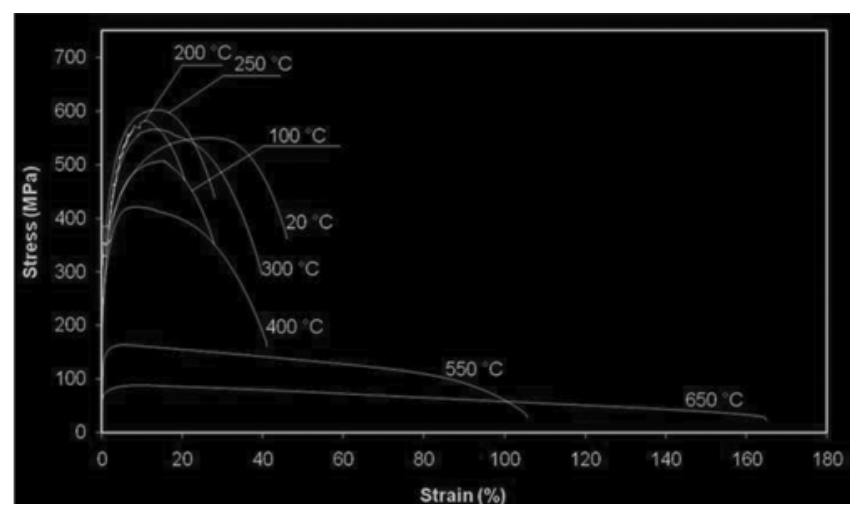

Figure 7. Stress-strain behaviour of S 355JO steel at elevated temperatures.
On the basis of tests performed at elevated temperatures, it is visible that ultimate and 0.2 offset yield strength exhibit usual behaviour for this kind of steel at these environmental conditions. Namely, ultimate tensile

Table 1. Mechanical properties of S 355JO steel at lowered temperatures.

\begin{tabular}{lcc}
\hline Temperature $\left({ }^{\circ} \mathrm{C}\right)$ & $\sigma_{0 \cdot 2}(\mathrm{MPa})$ & $\sigma_{\mathrm{m}}(\mathrm{MPa})$ \\
\hline 0 & $431 \cdot 6$ & $570 \cdot 6$ \\
-10 & $435 \cdot 2$ & $561 \cdot 3$ \\
-30 & $397 \cdot 9$ & $576 \cdot 0$ \\
-50 & 417.7 & $603 \cdot 2$ \\
-70 & $467 \cdot 1$ & 618.4 \\
\hline
\end{tabular}

Table 2. Mechanical properties of S 355JO steel at elevated temperatures.

\begin{tabular}{lcc}
\hline Temperature $\left({ }^{\circ} \mathrm{C}\right)$ & $\sigma_{0 \cdot 2}(\mathrm{MPa})$ & $\sigma_{\mathrm{m}}(\mathrm{MPa})$ \\
\hline 20 & $385 \cdot 7$ & $550 \cdot 6$ \\
100 & $354 \cdot 8$ & $507 \cdot 5$ \\
200 & $329 \cdot 4$ & $580 \cdot 7$ \\
250 & $306 \cdot 7$ & $601 \cdot 9$ \\
300 & $250 \cdot 7$ & $565 \cdot 5$ \\
400 & $233 \cdot 9$ & $420 \cdot 8$ \\
550 & $129 \cdot 7$ & $163 \cdot 5$ \\
650 & $64 \cdot 5$ & $87 \cdot 8$ \\
\hline
\end{tabular}
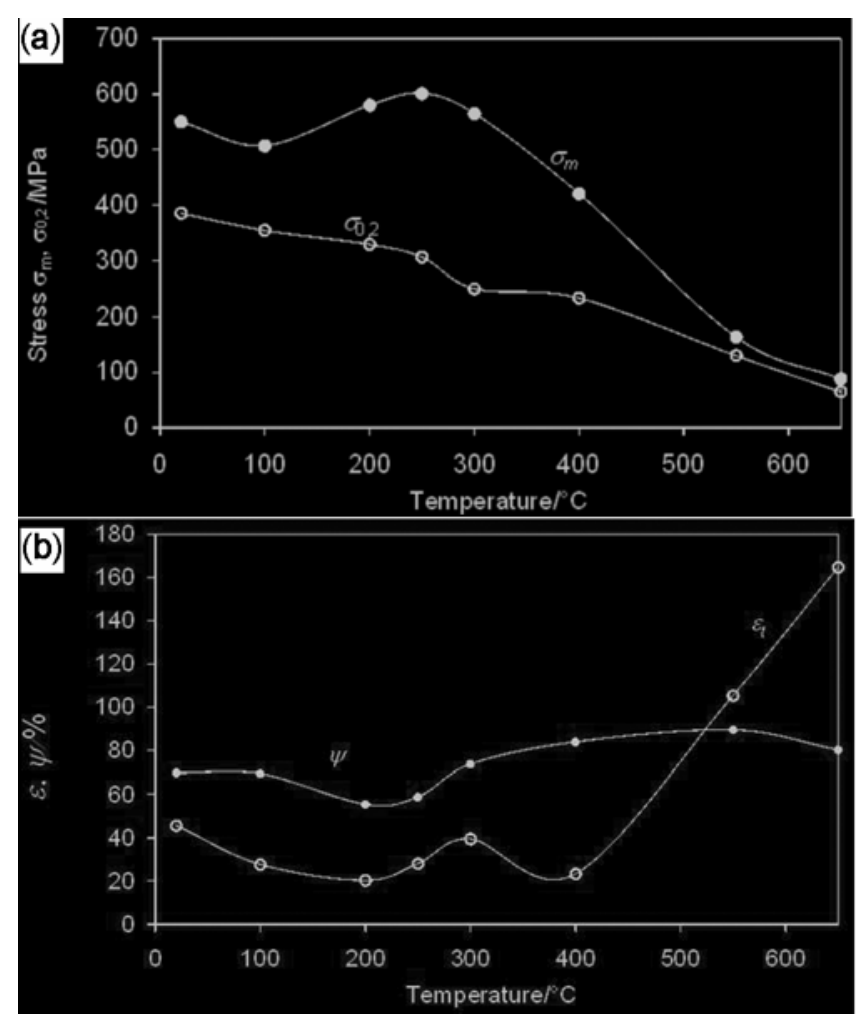

Figure 8. Effect of elevated temperature on mechanical properties, elongation and reduction in area: (a) mechanical properties, $\sigma_{\mathrm{m}}$ and $\sigma_{0.2}$ vs temperature and (b) specimen's elongation and reduction in area vs temperature. 
strength decreases with temperature increasing till $100^{\circ} \mathrm{C}$, and after that it increases with temperature increasing till $250^{\circ} \mathrm{C}$. In the further regime of temperature increasing, ultimate tensile strength decreases.

If some explicit function for stress-strain relationship is necessary, there are several options available, see Yang et al (2003) for one procedure.

\subsection{Notch impact energy determination}

Fracture mechanics may be described as a discipline underlying design against fracture. Formal fracture analysis uses mechanics concept. To define nominal stress at which fracture takes place, material property, $K_{\mathrm{IC}}$, called fracture toughness (plane-strain fracture toughness), was introduced into the equation. Fracture toughness is straightforwardly measured by a number of standard tests (Courtney 1997). These tests are described by ASTM E 399-90 standard. For example, for a material containing an intentionally sharp crack and subjected to tensile test, stress is measured and $K_{\text {IC }}$ may be calculated. A hardness

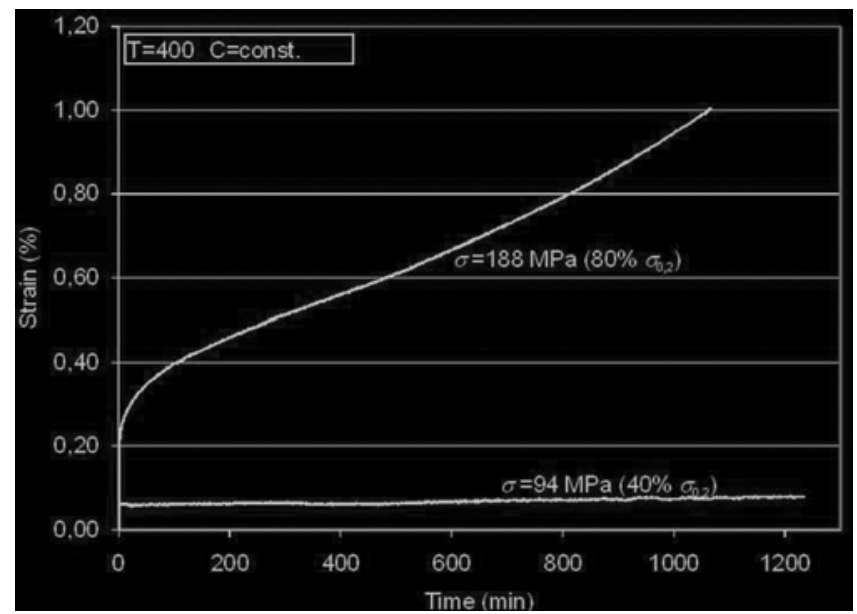

Figure 9. Creep response of S 355JO steel at $T=400^{\circ} \mathrm{C}$.

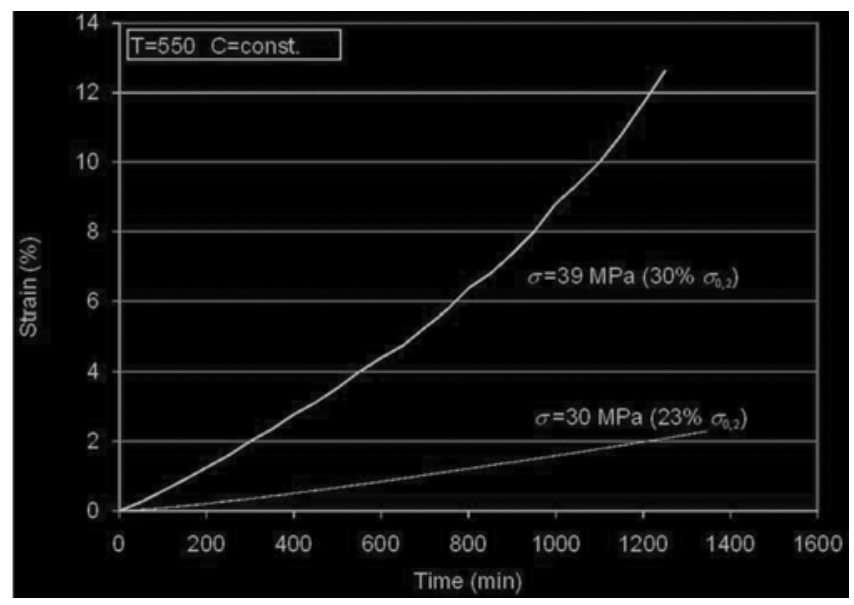

Figure 10. Creep response of S $355 \mathrm{JO}$ steel at $T=550^{\circ} \mathrm{C}$ test can be used to determine fracture toughness of brittle materials. While fracture toughness is the most useful material property in mentioned design against fracture, there are other tests that provide a measure of fracture resistance. In that way, an impact test, widely used in the ferrous metals and plastics industry, is one of such tests and it is performed by Charpy pendulum impact machine (figure 3). Although the Charpy test is very popular, the notch acuity, the temperatures as well as the strain rate used in the test do not have to be representative of the conditions in which many steels are used. Therefore, the results of Charpy impact tests cannot be used directly to predict in-service behaviour and failure characteristics, because fracture mode depends not only on the properties of the steel, but also on the mentioned parameters. The advantage of the Charpy test is that it is a quick and relatively easy test to be performed. It is a very useful test for assessing the quality of a product. Also, some disadvantages exist. The energy to fracture depends on the sample geometry. Many steel structures or components do not contain notches of the type used in Charpy tests. Thus, it may be misleading to employ the results directly in real industrial applications. Comparing experimentally obtained result for fracture toughness, $K_{\mathrm{IC}}$, for different materials and impact toughness, $K$, calculated from experimentally obtained notch impact energy for the same mentioned materials at a temperature of $20^{\circ} \mathrm{C}$, we have proposed the following relationship between $K_{\mathrm{IC}}$ and $K$ :

$$
K_{\text {IC }}^{2}=1 / 20(E K)(1+v) \text {. }
$$

By (1) it is possible to determine an average value of $K_{\text {IC. }}$

In this equation there are: $K_{\mathrm{IC}}(\mathrm{MPa} \sqrt{m})$, fracture toughness; $E$ (MPa), modulus of elasticity; $K\left(\mathrm{~J} / \mathrm{mm}^{2}\right)$, impact toughness, and $v$, Poisson's ratio. Impact toughness, $K$, was calculated as

$$
K=C V N / A \text {. }
$$

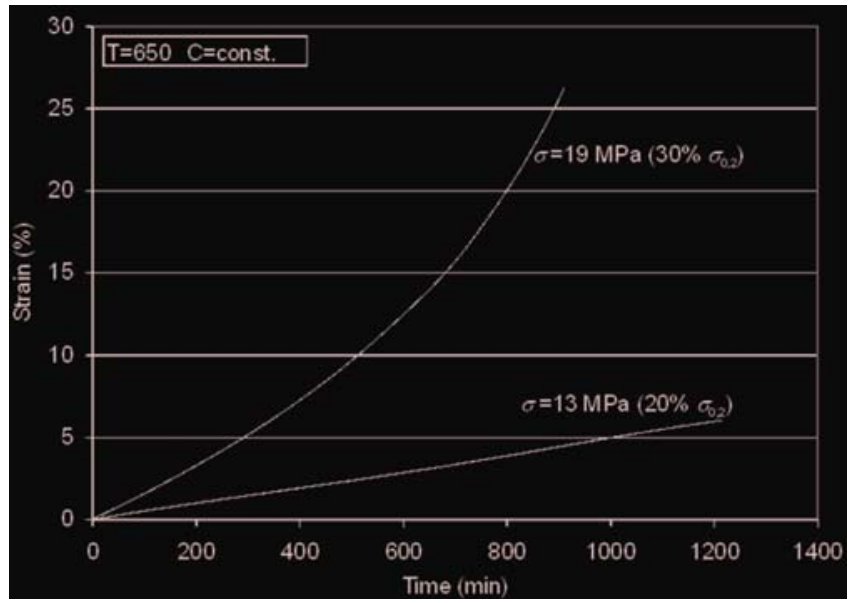

Figure 11. Creep response of S $355 \mathrm{JO}$ at $T=650^{\circ} \mathrm{C}$ 
In (2), $C V N$ is Charpy-V-Notch experimentally obtained impact energy $(J)$, and $A\left(\mathrm{~mm}^{2}\right)$ is cross-sectional area of Charpy impact specimen at the place of notch.

The type of specimen notch depends largely upon the characteristic of the material to be used. In the present case, $2 \mathrm{~V}$ notch was used. For Poisson ratio of this material, the value of $v=0.3$ was adopted and cross-sectional area of the specimen was $A=80 \mathrm{~mm}^{2}$.

According to the used specimen as well as experimental average data obtained for $C V N$ and $E$ of this material:

$$
C V N=94 J, E=211000 \mathrm{MPa},
$$

the following values were calculated:

$$
K=1 \cdot 175 \mathrm{~J} / \mathrm{mm}^{2} \text {, and } K_{\mathrm{IC}}=127 \mathrm{MPa} \sqrt{m} .
$$

\section{Creep tests}

Creep tests were carried out at constant temperature for selected constant stresses.

\subsection{Constant temperature, $T=400^{\circ} \mathrm{C}$ and constant} stress:

$$
\sigma_{1}=0.40 \sigma_{0.2}=94 \mathrm{MPa} ; \sigma_{2}=0.80 \sigma_{0.2}=188 \mathrm{MPa} .
$$

Creep behaviour at the mentioned conditions is presented in figure 9 .

\subsection{Constant temperature, $T=550^{\circ} \mathrm{C}$ and constant} stress

$$
\sigma_{1}=0.23 \sigma_{0.2}=30 \mathrm{MPa} ; \sigma_{2}=0.30 \sigma_{0.2}=39 \mathrm{MPa} .
$$

Creep behaviour at the mentioned conditions is presented in figure 10 .

\subsection{Constant temperature, $T=650^{\circ} \mathrm{C}$ and constant stress}

$$
\sigma_{1}=0 \cdot 20 \sigma_{0.2}=13 \mathrm{MPa} ; \sigma_{2}=0 \cdot 30 \sigma_{0.2}=19 \mathrm{MPa} .
$$

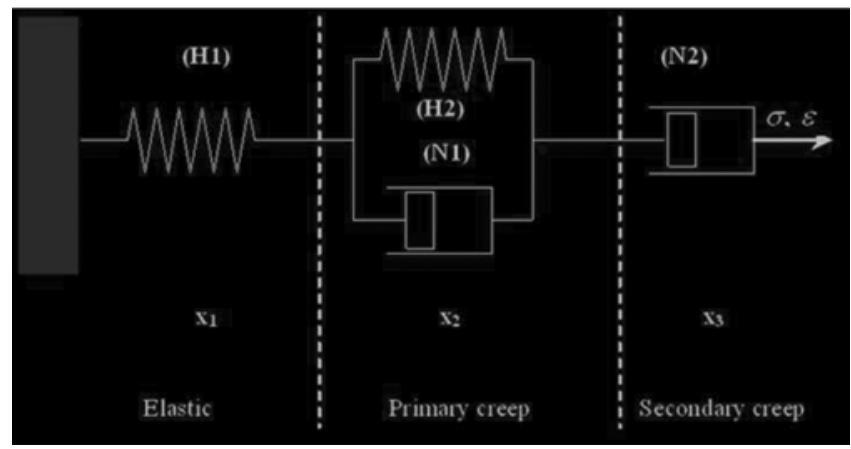

Figure 12. Rheological model
Creep behaviour at the mentioned conditions is presented in figure 11.

On the basis of creep test results, it can be said that this kind of steel, generally, is not enough creep resistant when long-time creep regime is considered. If a structure is subjected to enough low stress level according to $0 \cdot 2$ offset yield strength and in a regime of short-time creep e.g. fire condition, then this steel may be treated as suitable till the temperature of $500^{\circ} \mathrm{C}$.

\section{Creep behaviour simulation by using the rheological model}

Simulation of material creep response is based on rheological model (figure 12).

The proposed rheological model is known as Burger's model and it can be suitable for simulation of instantaneous and steady-state creep stages. For the mentioned rheological model the following basic equations for both strain and strain rate can be given:

$$
\varepsilon=\varepsilon^{x 1}+\varepsilon^{x 2}+\varepsilon^{x 3} ; \quad \dot{\varepsilon}=\dot{\varepsilon}^{x 1}+\dot{\varepsilon}^{x 2}+\dot{\varepsilon}^{x 3},
$$

while for stress in each segment of the model may be written as

$$
\left.\begin{array}{l}
\sigma=\sigma^{x 1}=\sigma^{x 2}=\sigma^{x 3}, \\
\sigma^{x 1}=\sigma^{H 1}=E_{1} \varepsilon^{x 1} \\
\sigma^{x 2}=\sigma^{N 1}+\sigma^{H 2}=\eta_{1} \dot{\varepsilon}^{x 2}+E_{2} \varepsilon^{x 2} \\
\sigma^{x 3}=\sigma^{N 2}=\eta_{2} \dot{\varepsilon}^{x 3}
\end{array}\right\} .
$$

In these equations, as well as in figure 12, $H$ means Hook and $N$ means Newton, respectively.

From the listed basic equations, after standard calculations, the following differential equation was obtained:

$$
\begin{aligned}
& \dot{\varepsilon}+\frac{E_{2}}{\eta_{2}} \varepsilon-\sigma \frac{E_{2}}{\eta_{1} \eta_{2}} t-\sigma\left(\frac{E_{2}}{\eta_{1} E_{1}}+\frac{\eta_{1}+\eta_{2}}{\eta_{1} \eta_{2}}\right)=0 \\
& \text { with } \varepsilon(t=0)=\frac{\sigma}{E_{1}} .
\end{aligned}
$$

The solution of the above equation is

$$
\varepsilon=\sigma\left[\frac{1}{E_{1}}+\frac{1}{E_{2}}\left(1-e^{\left(-E_{2} / \eta_{1}\right) t}\right)+\frac{t}{\eta_{2}}\right] .
$$

The material parameters $E_{2}, \eta_{1}, \eta_{2}$ are interpolated with regard to experimentally obtained creep curve and are presented in table 3 for temperature, $T=400^{\circ} \mathrm{C}$ and time, $400 \mathrm{~min}$.

Two creep curves, where one of them was experimentally obtained and second one was obtained by rheological model, are presented in figure 13. Both of the mentioned curves are related to $\mathrm{S} 355 \mathrm{JO}$ steel subjected to stress of $\sigma=188 \mathrm{MPa}$ at a temperature of $T=400^{\circ} \mathrm{C}$. 


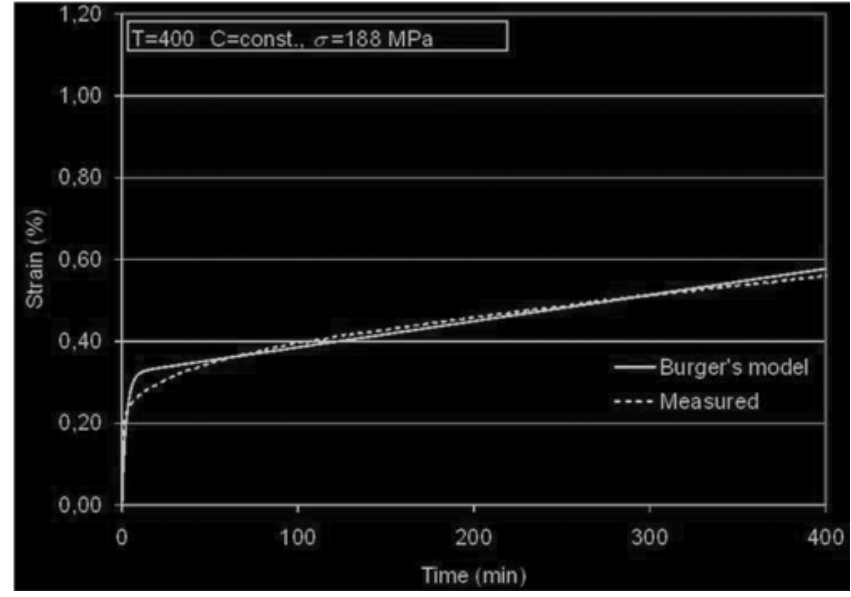

Figure 13. S 355JO steel-comparison of creep curves obtained by Burger's model and by test for the first $400 \mathrm{~min}$ of creep.

Table 3. Burger's model parameters for $\mathrm{S} 355 \mathrm{JO}$ steel at $400^{\circ} \mathrm{C}$ and time, $400 \mathrm{~min}$.

\begin{tabular}{lccc}
\hline Temperature & & & $E_{2}(\mathrm{MPa})$, \\
$\left({ }^{\circ} \mathrm{C}\right)$ & $\sigma(\mathrm{MPa})$ & $E_{1}(\mathrm{GPa})$ & $\begin{array}{l}\eta_{1}(\mathrm{MPa} \min ), \\
\eta_{2}(\mathrm{MPa} \min )\end{array}$ \\
\hline 400 & 188 & 171.9 & $E_{2}=586$ \\
& & & $\eta_{1}=1475$ \\
& & & $\eta_{2}=293814$ \\
\hline
\end{tabular}

\section{Conclusions}

Experimentally obtained data relating to mechanical properties as well as creep behaviour of structural steel under consideration, are of importance in structure design procedure. In the available literature, the authors did not find something similar about behaviour of considered steel at mentioned environmental conditions. Therefore, the appropriate experimental research was carried out according to the norms. Standard procedures were carefully followed and no limitations or difficulties in implementation were noticed. According to the presented results, some of the conclusions can be adopted. These results point out the trend of ultimate tensile strength and $0 \cdot 2$ offset yield strength at elevated and lowered temperatures as well as its creep resistance. It can be seen that ultimate strength level after temperature of $250^{\circ} \mathrm{C}$ decreases, while 0.2 offset yield strength level decreases during all of increasing temperature regime. Also, it is visible that this steel becomes practically useless in such environmental conditions where service temperature gains upon $500^{\circ} \mathrm{C}$. This remark is in accordance with creep resistance of the con- sidered material. Namely, S $355 \mathrm{JO}$ steel may be treated as creep resistant at a temperature of $400^{\circ} \mathrm{C}$ subjected to uniaxial stress level $<94 \mathrm{MPa}$, e.g. of $40 \%$ of $0 \cdot 2$ offset yield strength. In such environmental conditions where temperature increases over $500^{\circ} \mathrm{C}$, ultimate tensile strength and 0.2 offset yield strength become low and creep resistance may be treated as negligible.

\section{Acknowledgements}

The research presented in this paper was realized within the scientific project No. 069-0691736-1737 'Numerical analysis of structural response for specific service conditions' financially supported by the Ministry of Science, Education and Sport of the Republic of Croatia. Also, the authors would like to thank the participants from the Material Testing Laboratory, Department of Materials, Faculty of Engineering, Rijeka, for their contribution in determination of testing material composition.

\section{References}

Annual Book of ASTM Standards: Metal Test Methods and Analytical Procedures 2005 (Baltimore: ASTM International), Vol. 03.01

Brnic J, Turkalj G, Canadija M and Lanc D 2009 Mat. Sci. Eng. A-Struct. 49923

Collins J A 1993 Failure of materials in mechanical design (New York: John Wiley \& Sons)

Courtney T H 1997 Fundamental structure-property relationships in engineering materials, ASM Handbook, Materials selection and design (ed.) G Deiter (Materials Park, OH: ASM International), Vol. 20, p. 336

Hayward A, Sadler N and Tordoff D 2002 Steel bridges (London: The British Construction Steelwork Association Ltd)

International Standard 2000 Metallic materials-tensile testing at low temperature, ISO 15579: (E)

Outinen J and Makelainen P 2006 Fire Mater. 28237

Outinen J, Kesti J and Makelainen P 1997 J. Constr. Steel Res. 42161

Raghavan V 2004 Materials science and engineering (New Delhi: Prentice - Hall of India)

Stephens R I, Fatemi A, Stephens R R and Fuchs H O 2001 Metal fatigue in engineering (New York: John Wiley \& Sons)

Timmins P F 1997 Failure control in process operations, ASM Handbook (ed.) G Dieter (Materials Park, OH: ASM International), Vol. 19, p. 468

Veljkovic M and Johansson B 2004 J. Constr. Steel. Res. 60 535

Wald F et al 2006 Fire Saf. J. 41509

Yang Y Y, Mahfoufm M and Linkens D A 2003 J. Mater. Sci. Technol. 195 